Amanda Mauro Rodrigues Pimentel

Remoção de Co(II) e Mn(II) de Soluções Aquosas Utilizando a Biomassa $R$. opacus

Dissertação apresentada como requisito parcial para obtenção do título de Mestre pelo Programa de PósGraduação em Engenharia de Materiais e de Processos Químicos e Metalúrgicos do Departamento de Engenharia de Materiais da PUC-Rio.

Orientador: Maurício Leonardo Torem Co-Orientadora: Iranildes Daniel dos Santos 


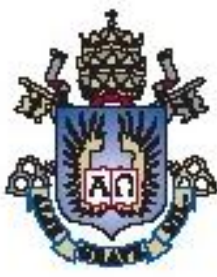

Amanda Mauro Rodrigues Pimentel

\title{
Remoção de Co(II) e Mn(II) de Soluções Aquosas Utilizando a Biomassa $R$. opacus
}

\begin{abstract}
Dissertação apresentada como requisito parcial para obtenção do título de Mestre pelo Programa de PósGraduação em Engenharia de Materiais e de Processos Químicos e Metalúrgicos do Departamento de Engenharia de Materiais da PUC-Rio. Aprovada pela Comissão Examinadora abaixo assinada.
\end{abstract}

Prof $^{\circ}$. Maurício Leonardo Torem

Orientador

Departamento de Engenharia de Materiais - PUC - Rio

Profa. Iranildes Daniel dos Santos

Co-Orientadora

Departamento de Engenharia de Materiais - PUC - Rio

Prof $^{\circ}$. Paulo Sergio Moreira Soares

Centro de Tecnologia Mineral - CETEM

Prof $^{\circ}$. Roberto José de Carvalho

Departamento de Engenharia de Materiais - PUC - Rio

Prof. José Eugenio Leal

Coordenador Setorial do Centro Técnico Científico - PUC - Rio 
Todos os direitos reservados. É proibida a reprodução total ou parcial do trabalho sem autorização da universidade, do autor e do orientador.

\section{Amanda Mauro Rodrigues Pimentel}

Graduou-se em Ciências Biológicas pela Universidade Severino Sombra em 2006.

Ficha Catalográfica

Pimentel, Amanda Mauro Rodrigues

Remoção de $\mathrm{Co}(\mathrm{II})$ e $\mathrm{Mn}$ (II) de soluções aquosas utilizando a biomassa R. opacus / Amanda Mauro Rodrigues Pimentel ; orientador: Maurício Leonardo Torem ; co-orientadora: Iranildes Daniel dos Santos. -2011.

135 f. : il. (color.) ; $30 \mathrm{~cm}$

Dissertação (Mestrado)-Pontifícia Universidade Católica do Rio de Janeiro, Departamento de Engenharia de Materiais, 2011.

Inclui bibliografia

1. Engenharia de materiais - Teses. 2. Biossorção. 3. Biomassa. 4. Tratamento de efluentes. 5. Metais pesados. I. Torem, Maurício Leonardo. II. Santos, Iranildes Daniel dos. III. Pontifícia Universidade Católica do Rio de Janeiro. Departamento de Engenharia de Materiais. IV. Título.

CDD: 620.11 
Dedico esta dissertação aos meus pais, Rosana Mauro Rodrigues e José Armando Pimentel, ao meu padrasto José Sacramento Silveira e ao meu irmão Pedro Henrique. 


\section{Agradecimentos}

Aos meus orientadores: Prof. Maurício Leonardo Torem e Prof. Iranildes Daniel dos Santos pelo apoio e confiança depositados durante a realização deste trabalho.

À CAPES, CNPq, e PUC-Rio pelo auxílio financeiro concedido.

Ao Laboratório de Espectroscopia de Absorção Atômica do Departamento de Química da PUC-Rio pelas análises de absorção atômica.

Aos amigos, professores, pesquisadores e funcionários do Departamento de Engenharia de Materiais da PUC-Rio, pelos ensinamentos e sugestões durante a realização deste trabalho. 


\section{Resumo}

Pimentel, Amanda Mauro Rodrigues; Torem, Maurício Leonardo. Remoção de Co(II) e $\mathrm{Mn}$ (II) de Soluções Aquosas Utilizando a Biomassa R. Opacus. Rio de Janeiro, 2011. 135p. Dissertação de Mestrado - Departamento de Engenharia de Materiais, Pontifícia Universidade Católica do Rio de Janeiro.

A busca por tecnologias alternativas e de baixo custo operacional para a remoção de metais em efluentes tem direcionado a atenção para a biossorção. Recentemente vários materiais de origem biológica, como bactérias e resíduos agro-industriais têm sido utilizados para a remoção de íons metálicos de efluentes industriais. A biossorção de metais pesados por espécies biológicas envolve vários mecanismos que, em geral, dependem das espécies biológicas utilizadas e do processamento da biomassa. O cobalto e o manganês são amplamente utilizados em muitas aplicações industriais, e consequentemente, estão presentes nos efluentes provenientes de vários processos industriais, como por exemplo na mineração e produção de ligas. O objetivo deste trabalho foi investigar a eficiência do Rhodococcus opacus, que apresenta vários grupamentos fenólicos e carboxílicos (capazes de interagir com íons metálicos em solução), como adsorvente para a remoção de Co(II) e $\mathrm{Mn}$ (II) de soluções aquosas, visando futuras aplicações para o tratamento de efluentes. A caracterização física da superfície do $R$. opacus foi realizada com MEV, potencial zeta e análises de FTIR. A biomassa, $R$. opacus, foi previamente tratada com 0,1 mol.L ${ }^{-1} \mathrm{NaOH}$ e usada em todos os experimentos de biossorção. Todos os testes de biossorção foram realizados em batelada e os parâmetros avaliados foram: $\mathrm{pH}$, concentração da biomassa e do metal, tempo de contato e temperatura. Os melhores valores de pH para a biossorção de $\mathrm{Co}$ (II) e $\mathrm{Mn}$ (II) foram 7,0 e 5,0, respectivamente. Para ambos os metais estudados, a capacidade de biossorção específica foi maior em soluções contendo baixas concentrações de metais. Para os dois metais, o processo de biossorção foi melhor descrito pelo modelo de Langmuir e pelo modelo cinético de pseudo segunda ordem. Os parâmetros termodinâmicos como $\Delta \mathrm{G}, \Delta \mathrm{S}$ e $\Delta \mathrm{H}$ foram calculados e os processos de biossorção para a remoção do Co(II) e do Mn(II) a 
partir de soluções aquosas foram consideradas reações endotérmicas e exotérmicas, respectivamente. Este trabalho mostra que o $R$. opacus pode ser aplicado para a remoção de íons de Co(II) e Mn(II) de soluções aquosas. Após 180 minutos de contato da biomassa com as soluções contendo Co(II) e $\mathrm{Mn}$ (II), $84 \%$ e $97 \%$ dos íons metálicos presentes em solução foram removidos.

\section{Palavras-chave}

Biossorção; Biomassa; Tratamento de efluentes; Metais Pesados. 


\section{Abstract}

Pimentel, Amanda Mauro Rodrigues; Torem, Maurício Leonardo (Advisor). Removal of $\mathrm{Co}$ (II) and $\mathrm{Mn}$ (II) from Aqueous Solutions Using R. Opacus Biomass. Rio de Janeiro, 2011. 135p. MSc. Dissertation - Departamento de Engenharia de Materiais, Pontifícia Universidade Católica do Rio de Janeiro.

The search for alternative technologies and low operating cost for removal of heavy metals from effluent has directing attention to biosorption. Recently, various biological materials, such as bacteria and agro-waste, have been used for removal of metallic ions from industrial effluents. Biosorption of heavy metals by biological species involves several mechanisms that, in general, depending on the type of specie used and biomass processing procedure. Cobalt and manganese are widely used in many industrial applications, consequently they are present in effluent derived from various industrial processes, for example: mining, alloy production. The objective of this work is to investigate the efficiency of Rhodococcus opacus, which presents various phenolic and carboxylic groups (able to interact with metal ions in solution), as an adsorbent for the removal of $\mathrm{Co}$ (II) and $\mathrm{Mn}$ (II) from aqueous solutions, aiming future applications for the treatment of effluents. Surface physical characterization of $R$. opacus was carried by MEV, zeta potential and FTIR analysis. The biomass, $R$. opacus, was previously treated with 0.1 mol.L-1 $\mathrm{NaOH}$ solution and used in all biosorption experiments. All the biosorption tests were carried out in batch and the parameters evaluated were: $\mathrm{pH}$, concentration of biomass and metal, contact time and temperature. The best $\mathrm{pH}$ value for biosorption of $\mathrm{Co}$ (II) and $\mathrm{Mn}$ (II) were 7.0 and 5.0 respectively. For both metal studied, the specific biosorption capacity was higher in solutions containing low metals concentrations. For both metals, the biosorption process was better described by the Langmuir and pseudosecond-order kinetic models. The thermodynamics parameters, such as $\Delta \mathrm{G}, \Delta \mathrm{S}$ and $\Delta \mathrm{H}$ were calculated and the biosorption process for $\mathrm{Co}$ (II) and $\mathrm{Mn}$ (II) removal from the aqueous solutions were considered endothermic and exothermic reactions, respectively. This work shown the $R$. opacus can be applied for 
removal Co(II) and Mn(II) ions from aqueous solutions. After 180 min contact of biomass with solutions containing $\mathrm{Co}(\mathrm{II})$ and $\mathrm{Mn}(\mathrm{II}), 84 \%$ and $97 \%$ of the metallic ion present in the solutions were removed.

\section{Keywords}

Biosorption; Biomass; Wastwaters treatment; Heavy metals. 


\section{Sumário}

1 Introdução

2 Objetivos 22

2.1. Objetivo Geral 22

2.2. Objetivos Específicos 22

3 Revisão Bibliográfica 23

3.1. Metais pesados 23

3.2. Contaminação por metais pesados - Um problema ambiental 25

3.3. Águas residuais 26

3.4. Padrões de qualidade da água e de lançamento de efluentes 28

3.5. Cobalto 30

3.5.1. Aplicabilidade do Cobalto 31

3.5.2. Toxicidade 33

3.5.3. Toxicodinâmica 33

3.6. Manganês 34

3.6.1. Aplicabilidade do Manganês 35

$\begin{array}{ll}\text { 3.6.2. Toxicidade } & 37\end{array}$

3.6.3. Toxicodinâmica 38

3.7. Tecnologias de tratamento de efluentes: Métodos convencionais 38

3.7.1. Precipitação química 39

3.7.2. Troca iônica 39

3.7.3. Filtração por membranas 40

3.7.4. Flotação 40

3.7.5. Floculação/Coagulação 41

3.7.6. Adsorção $\quad 41$

3.8. Biossorção 42

3.8.1. Mecanismos da biossorção 4

3.8.2. Tipos de mecanismos $\quad 44$ 
3.8.3. Variáveis que afetam a biossorção 46

3.9. Rhodococcus opacus 50

3.10. Isotermas de adsorção 53

3.10.1. Isoterma de Langmuir $\quad 56$

3.10.2. Isoterma de Freundlich $\quad 57$

3.11. Cinética da biossorção 58

3.11.1. Modelos da cinética de adsorção 59

3.11.2. Influência da temperatura na velocidade de reação 59

3.12. Parâmetros Termodinâmicos 60

4 Materiais e Métodos 62

4.1. Obtenção e preparo da biomassa 62

4.1.1. Tratamento da biomassa com $\mathrm{NaOH}$

4.1.2. Determinação da concentração da biomassa 63

4.2. Preparo da solução estoque dos íons Co(II) e Mn(II) 64

4.3. Caracterização da supefície da R. opacus 64

4.3.1. Microscopia Eletrônica de Varredura 65

4.3.2. Espectroscopia de Infravermelho 65

4.3.3. Potencial Zeta 66

4.4. Ensaios de biossorção 66

4.4.1. Análise quantitativa da concentração dos metais 69

5 Resultados e discussão $\quad 70$

5.1. Caracterização da biomassa antes e após a interação com íons Co(II) e Mn(II) 70

5.1.1. Potencial Zeta 70

5.1.2. Análises de MEV e EDS 72

5.1.3. Caracterização por Infravermelho 76

5.2. Estudos de biossorção em batelada 80

5.2.1. Influência da variação do $\mathrm{pH}$

5.2.2. Efeito da concentração da biomassa 84

5.2.3. Efeito da concentração inicial do metal e isotermas 88

5.2.4. Avaliação do tempo de equilíbrio da biossorção do Co(II)

e Mn(II) pelo R.opacus 97 
5.2.5. Influência da temperatura no processo de biossorção

5.2.6. Influência da temperatura aplicada a cinética de pseudo-segunda ordem

108

5.2.7. Estudos termodinâmicos para o processo de biossorção do $\mathrm{Co}$ (II) e Mn(II) 


\section{Lista de figuras}

Figura 1. Destino dos metais pesados descartados no meio ambiente e a sua acumulação ao longo da cadeia alimentar (Ferraz, 2007).

Figura 2. A distribuição do consumo de água no mundo segundo a

ONU (Consumo Sustentável: Manual de educação, 2005).

Figura 3. O mercado mundial do cobalto em 2009 (Cobalt Development Institute, 2010).

Figura 4. Quantidade, em toneladas, de minério de manganês exportadas pelo Brasil Segundo o Instituto Brasileiro de Mineração (IBRAM).

Figura 5. Solutos retidos pelas diferentes membranas (Gomes, 2009).

Figura 6. Esquema resumido da biossorção de metais pesados em solução aquosa por biomassas (Benviendo da Luz et al., 2002).

Figura 7. a) Micrografia em MEV do R. opacus. b) Micrografia mostrando uma célula de Rhodococcus opacus contendo vários grânulos de lipídios (TAG) como única fonte de carbono e energia (Alvarez, 2010). Imagem: F. Mayer da Universidade Georg-August de Gottingen, Alemanha.

Figura 8. Modelo de organização da parede celular do gênero

Rhodococcus. (Adaptado de Minnikin, 1991).

Figura 9. À esquerda, a composição química do peptideoglicano e à direita a composição química do ácido teióico.

Figura 10. Esquema simplificado de um sistema de adsorção em equilíbrio. $\quad 54$

Figura 11. Isotermas de adsorção (McCabe et al., 2001).

Figura 12. Classificação dos diferentes tipos de isotermas de adsorção segundo Brunauer et al. (1940).

Figura 13. Obtenção da biomassa. a) Colônia bacteriana Rhodococcus opacus em meio sólido; b) Cultivo em meio líquido em incubadora com plataforma de rotação horizontal; c)Inativação da bactéria em autoclave; d) Concentrado de biomassa obtido após a centrifugação; e) Determinação da concentração da biomassa através do peso seco.

Figura 14. Representação simplificada dos ensaios de biossorção.

Figura 15. Curva de calibração obtida por espectrofotometria de absorção 
atômica para o $\mathrm{Co}(\mathrm{II})$ e $\mathrm{Mn}(\mathrm{II})$.

Figura 16. Potencial zeta da bactéria $R$. opacus em função do $\mathrm{pH}$ para

diferentes condições: biomassa, biomassa carregada com Co e a

biomassa carregada com $\mathrm{Mn}$. $\mathrm{NaCl}$ a 0,001 mol.L $\mathrm{L}^{-1}$ e 0,2 g. $\mathrm{L}^{-1}$ de biomassa.

Figura 17. A) Biomassa sem pré-tratamento. B) Biomassa pré-tratada

com 0,1 mol.L $\mathrm{L}^{-1} \mathrm{NaOH}$

Figura 18. A) Biomassa carregada com Co. B) Biomassa carregada com Mn. 74

Figura 19. Espectros de EDS. 1: Biomassa carregada com Co apresentada

na Figura 18A. 2: Biomassa carregada com Mn apresentada na Figura 18B.

75

Figura 20. Espectros de IV-TF da biomassa $R$. opacus.

Figura 21. Principais bandas presentes na biomassa $R$. opacus .

Figura 22. Efeito do pH na biossorção de Co(II) pela biomassa $R$.

opacus. Concentração inicial do metal: $50 \mathrm{mg} . \mathrm{L}^{-1}$; concentração da

biomassa: $\quad 1,0$ g. $\mathrm{L}^{-1}$; temperatura: $25^{\circ} \mathrm{C}$; tempo de contato: $180 \mathrm{~min}$.

Figura 23. Efeito do pH na biossorção de Mn(II) pela biomassa

R. opacus. Concentração inicial do metal: $50 \mathrm{mg} . \mathrm{L}^{-1}$; concentração da

biomassa: $\quad 1,0$ g. $\mathrm{L}^{-1}$; temperatura: $25^{\circ} \mathrm{C}$; tempo de contato: $180 \mathrm{~min}$.

Figura 24. Efeito da concentração da biomassa na biossorção de Co(II) por

R. opacus. Concentração inicial do metal: $50 \mathrm{mg} . \mathrm{L}^{-1}$; $\mathrm{pH} 7$;

temperatura: $25^{\circ} \mathrm{C}$; tempo de contato: $180 \mathrm{~min}$.

Figura 25. Efeito da concentração da biomassa na biossorção de Mn(II) por

R. opacus. Concentração inicial do metal: $50 \mathrm{mg} . \mathrm{L}^{-1}$; pH 5;

temperatura: $25^{\circ} \mathrm{C}$; tempo de contato: $180 \mathrm{~min}$.

Figura 26. A) isoterma de adsorção do $\mathrm{Co}\left(\mathrm{pH} 7 ; 4\right.$ g. $\mathrm{L}^{-1}$ de biomassa;

$25^{\circ} \mathrm{C}$; 180 minutos de contato); B) isoterma de adsorção do

Mn (pH 5; 3 g. $\mathrm{L}^{-1}$ de biomassa; $25^{\circ} \mathrm{C} ; 180$ minutos de contato).

Figura 27. Isotermas de Langmuir e Freundlich para a biossorção do

Co (pH 7; 4 g. $\mathrm{L}^{-1}$ de biomassa; $25^{\circ} \mathrm{C} ; 180$ minutos de contato).

Isotermas de Langmuir e Freundlich para a biossorção do

Mn (pH 5; 3 g.L. -1 $^{-1}$ biomassa; $25^{\circ} \mathrm{C} ; 180$ minutos de contato).

Figura 28. Efeito da biossorção de $\mathrm{Co}(\mathrm{II})\left(\mathrm{pH} 7 ; 4 \mathrm{~g} . \mathrm{L}^{-1}\right.$ de biomassa;

$42 \mathrm{mg} . \mathrm{L}^{-1}$ ) e do $\mathrm{Mn}(\mathrm{II})$ (pH 5; 3g. $\mathrm{L}^{-1}$ de biomassa; $5 \mathrm{mg} . \mathrm{L}^{-1}$ ) em função do tempo de contato entre a solução metálica e a biomassa $R$. opacus. 
Figura 29. Modelo linear de pseudo-primeira ordem para remoção de Co(II) e Mn(II) pela biomassa de $R$. opacus.

Figura 30. Modelo linear de pseudo-segunda ordem para remoção de Co(II) e Mn(II) pela biomassa de $R$. opacus.

Figura 31. Influência da temperatura na remoção do Co(II) por R. opacus. 105

Figura 32. Influência da temperatura na remoção do Mn(II) por R. opacus. 107

Figura 33. Modelo cinético de pseudo-segunda ordem aplicado a

biossorção de $\mathrm{Co}(\mathrm{II})$.

Figura 34. Modelo cinético de pseudo-segunda ordem aplicado a biossorção de $\mathrm{Mn}(\mathrm{II})$.

Figura 35. Cálculo da energia de ativação a partir da equação de Arrhenius.

A) Reação de adsorção do Co(II); B) Reação de adsorção do Mn(II).

Figura 36. Comparação percentual da remoção do $\operatorname{Co}($ II) a

diferentes temperaturas.

Figura 37. Comparação percentual de remoção do Mn(II) a

diferentes temperaturas.

Figura 38. Isotermas de Langmuir para biossorção do Co(II) nas temperaturas de 25,35 e $45^{\circ} \mathrm{C}$.

Figura 39. Correlação entre a constante de equilíbrio e a

temperatura na biossorção do $\mathrm{Co}(\mathrm{II})$ por $R$. opacus.

Figura 40. Isotermas de Langmuir para biossorção do Mn(II) nas temperaturas de 25,35 e $45^{\circ} \mathrm{C}$.

Figura 41. Correlação entre a constante de equilíbrio e a temperatura na biossorção do Mn(II) por R. opacus. 


\section{Lista de tabelas}

Tabela 1. Função biológica e toxicidade para plantas e animais de alguns elementos-traço.

Tabela 2. Limites máximos para concentração de substâncias inorgânicas em água doce Classe 3. Resolução CONAMA 357/2005.

Tabela 3. Dispõe sobre condições e padrões de lançamento de efluentes de substâncias inorgânicas estabelecido pela resolução CONAMA 430/2011.

Tabela 4. Fontes de exposição ambiental ao cobalto mencionado na literatura (Alves e Della Rosa, 2003).

Tabela 5. Produção mundial de cobalto refinado e as reservas estimadas em 2009 para vários países (Cobalt Development Institute, 2010).

Tabela 6. Maiores produtores mundiais de minério de manganês (U.S. Geological Survey, 2010).

Tabela 7. Principais características dos tipos de isotermas apresentadas na Figura 9 (Lavarda, 2010) 55

Tabela 8. Condições experimentais utilizadas no processo de biossorção

Tabela 9. Porcentagem de concentração mássica e atômica dos elementos encontrados na biomassa $R$. opacus.

Tabela 10. Possíveis grupos funcionais e os números de onda das principais bandas de absorção identificadas nas amostras analisadas (Sharma, 2001; Silverstein et al. 2007).

Tabela 11. Efeito da concentração inicial de Co(II) e Mn(II) nos experimentos de biossorção com $R$. opacus.

Tabela 12. Constantes das isotermas de Langmuir e Freundlich obtidas a partir da adsorção dos íons Co(II) e Mn(II) pela biomassa $R$. opacus.

Tabela 13. Valores de $\mathrm{R}_{\mathrm{L}}$ para a biossorção dos íons Co(II) e Mn(II) em diferentes concentrações iniciais, pela biomassa bacteriana $R$. opacus.

Tabela 14. Porcentagem e captação dos íons em função do tempo.

Co: $\mathrm{pH} 7 ; \quad 4$ g. $\mathrm{L}^{-1}$ de biomassa; 42 mg. $\mathrm{L}^{-1}$ de Co(II). Mn: pH 5;

3g. $\mathrm{L}^{-1}$ de biomassa; $5 \mathrm{mg} . \mathrm{L}^{-1}$ de $\mathrm{Mn}(\mathrm{II})$.

Tabela 15. Parâmetros da cinética de adsorção do Co(II) e Mn(II) na 
biomassa $R$. opacus.

Tabela 16. Parâmetros cinéticos de pseudo-segunda ordem relacionados às temperaturas.

Tabela 17. Valores de $\mathrm{K}_{\mathrm{ads}}, \Delta \mathrm{G}, \Delta \mathrm{H}, \Delta \mathrm{S}$ na biossorção do cobalto por

R. opacus.

Tabela 18. Valores de $\mathrm{K}_{\mathrm{ads}}, \Delta \mathrm{G}, \Delta \mathrm{H}, \Delta \mathrm{S}$ na biossorção do $\mathrm{Mn}$ (II) por

R. opacus. 